\title{
Gene study raises fears for three-parent babies
}

\section{SALT LAKE CITY, UTAH}

A dramatic controversy has erupted over assisted-reproduction techniques that mix mitochondria from different women.

Mitochondria are the energy-generating structures in cells. Adding mitochondria from the egg of a second woman during in vitro fertilization is thought to boost the development of some eggs. It could also correct inherited diseases in which the mitochondria are defective.

But the approach is surrounded by ethical concerns, because the resulting babies have DNA from two mothers as well as the father. No teams are using the technique to treat women now, although such babies have been born in the past, and UK researchers are using it to create human embryos (see Nature 437, 305; 2005).

Now a mitochondrial researcher has reported workthat he says raises health worries too. “Our results suggest we shouldn't mix mitochondrial DNA from different women without thinking through the consequences," says Douglas Wallace, a biologist at the University of California, Irvine. Wallace described his research, on genetically engineered mice, on 26 October at a meeting of the American Society of Human Genetics in Salt Lake City, Utah.

Assisted-reproduction specialists say Wallace's conclusions are too rash. ${ }^{\alpha}$ To compare these artificial animals to assisted reproduction in humans is simply not correct," says Jacques Cohen, research director of the company Reprogenetics in West Orange, New Jersey.

Wallace's concerns come from a decade of research. Mitochondria carry genes that are passed unchanged from mother to child. But when Wallace's group created mice with mitochondria from two mothers, the mitochondria swapped genetic material in the offspring. Wallace says these mice had fewer pups - implying an effect on fertility and possibly on health.

Wallace is worried that assisted reproduction may subvert a natural system that protects mitochondria from changes that could perturb their function. "Mitochondrial DNA programs are highly adapted and integrated. It's extremely bad planning to put those different programs in
"We shouldn't mix mitochondrial DNA from women without thinking through the consequences." the same cell," Wallace says.

Other scientists are sceptical that DNA from different mitochondria would mix. Brendan Battersby of McGill University in Montreal, Canada, has also made mice with mixed mitochondria, and says he has never seen it happen: "I just don't believe it."

James Grifo of the New York University Fertility Center, who used mitochondrial transfer to create several babies in the late 1990 s, cautions that it is too early to draw conclusions from Wallace's results. "I'm not sure how they can make such broad statements about this being dangerous," he says.

ErikaCheck 